\title{
Persepsi Terhadap Lebar Koridor Utama pada Apartemen Ditinjau dari Respon Fisik Pengguna
}

\author{
Susy Budi Astuti ${ }^{1}$, Aria Weny Anggraita ${ }^{2}$, M.Husnul Azhar ${ }^{3}$, Angga Rubianto ${ }^{4}$ \\ 1,2,3,4 Jurusan Desain Interior, Institut Teknologi Sepuluh Nopember, Surabaya, Indonesia \\ kreasisusy@yahoo.com ${ }^{1}$, aria.weny@yahoo.com², m.husnulzone@gmail.com ${ }^{3}$, anggarubianto@gmail.com ${ }^{4}$
}

\begin{abstract}
ABSTRAK
Desain dapat mempengaruhi perilaku manusia dalam berinteraksi, termasuk interaksi antara manusia dengan ruang. Manusia mempunyai persepsi terhadap ruang yang berbedabeda, salah satunya dapat terlihat dari respon fisik perilaku pengguna. Koridor adalah sebuah jalan yang diapit oleh dinding dari sebelah kiri maupun kanan yang merupakan ruang-ruang disekitar jalan. Koridor sebagai ruang yang sering dilalui pengguna untuk melakukan berbagai aktivitas tentu dapat menjadi objek kajian dalam ilmu ergonomi. Dalam penelitian ini kami mengambil koridor utama Apartemen XY di Surabaya sebagai objek studi. Pemahaman akan ilmu ergonomi diperlukan untuk dapat menciptakan desain koridor yang ergonomis sehingga terjadi sirkulasi yang baik pada koridor.

Tujuan dari penelitian ini adalah mengetahui persepsi pengguna terhadap lebar koridor apartemen yang ditunjukkan melalui respon secara psikologis dan fisik mereka di koridor dengan berbagai aktivitas yang terjadi di dalamnya. Respon psikologis dan fisik pengguna dalam penelitian ini dapat menjadi acuan dalam mendesain lebar sebuah koridor yang ideal untuk sebuah apartemen.

Pada penelitian ini, referensi literatur berkaitan dengan ergonomi pada koridor serta psikologi manusia terhadap lingkungan di sekitarnya. Sebagai pendukung dari studi literatur, metode penelitian dilakukan dengan cara observasi aktifitas yaitu mengambil foto serta video pengguna apartemen yang melewati koridor pada pukul 18.00 - 19.00 WIB.
\end{abstract}

Kata Kunci : koridor, respon fisik, respon psikologis, psikologi ruang, perilaku manusia

\section{ABSTRACT}

Designs can affect human behavior in interactions, including interactions between people and space. Humans have a perception of the different spaces, one of which can be seen from the physical response of user behavior. Corridor is a road flanked by walls on the left and right who are spaces around the streets. Corridor as the room frequently traveled by user to perform a variety of activities can be the object study of the science of ergonomics. In this study, we took a main corridors Apartment $X Y$ in Surabaya as an object study. Ergonomics science needed to be able to create a corridor ergonomic design resulting in a good circulation in the corridor.

The purpose of this study was to determine the user's perception of the wide corridors of apartments shown by the response psychologically and physically they were in the corridor with a variety of activities that take place in it. The psychological and physical responses in this study can be a reference in designing the width of a corridor that is ideal for an apartment.

In this study, literature references related to ergonomics in the corridors as well as human psychology on the surrounding environment. The research method by observation that the activity of taking photos and video through the corridors of the apartment is at 6:00 p.m. to 19:00 pm.

Keywords : corridor, physical response, psychological response, space psychology, human behavior 


\section{PENDAHULUAN}

Sebuah bangunan komersial yang berfungsi sebagai tempat penginapan dan memiliki beberapa atau banyak kamar berjajar seperti hotel, apartemen, kost, hostel, dan lain-lain pada umumnya terdapat area sirkulasi yang disebut sebagai koridor. Koridor dapat mengacu kepada beberapa hal berikut: (Wikipedia)

1. Lorong dalam rumah; lorong yang menghubungkan antara suatu gedung dan gedung yang lain.

2. Tanah (jalan) sempit yang menghubungkan daerah terkurung.

3. Tanah yang menghubungkan dua bagian negara.

4. Jalur lalu lintas yang dimiliki suatu negara yang melintasi negara lain.

Koridor dalam konteks penelitian ini adalah koridor utama Apartemen XY di Surabaya. Koridor utama ini merupakan akses keluar masuk penghuni tiap unit apartemen, akses koridor ini digunakan sebagai area sirkulasi penghuni yang terkadang membutuhkan space lebih ketika penghuni membawa kebutuhan/keperluan harian seperti membawa barang belanjaan, atau ketika petugas servis dengan peralatannya, atau troly pengantar pesanan galon, dan lainlain, melewati koridor ini. Area koridor Apartemen XY cukup ramai pada jam pulang kantor, yaitu sekitar jam 18.00-19.00. Pada area koridor juga terdapat kotak surat untuk penghuni, sehingga aktivitas pada koridor selain sebagai akses penghuni untuk keluar masuk apartemen, juga terdapat aktivitas mengecek kotak surat oleh penghuni.

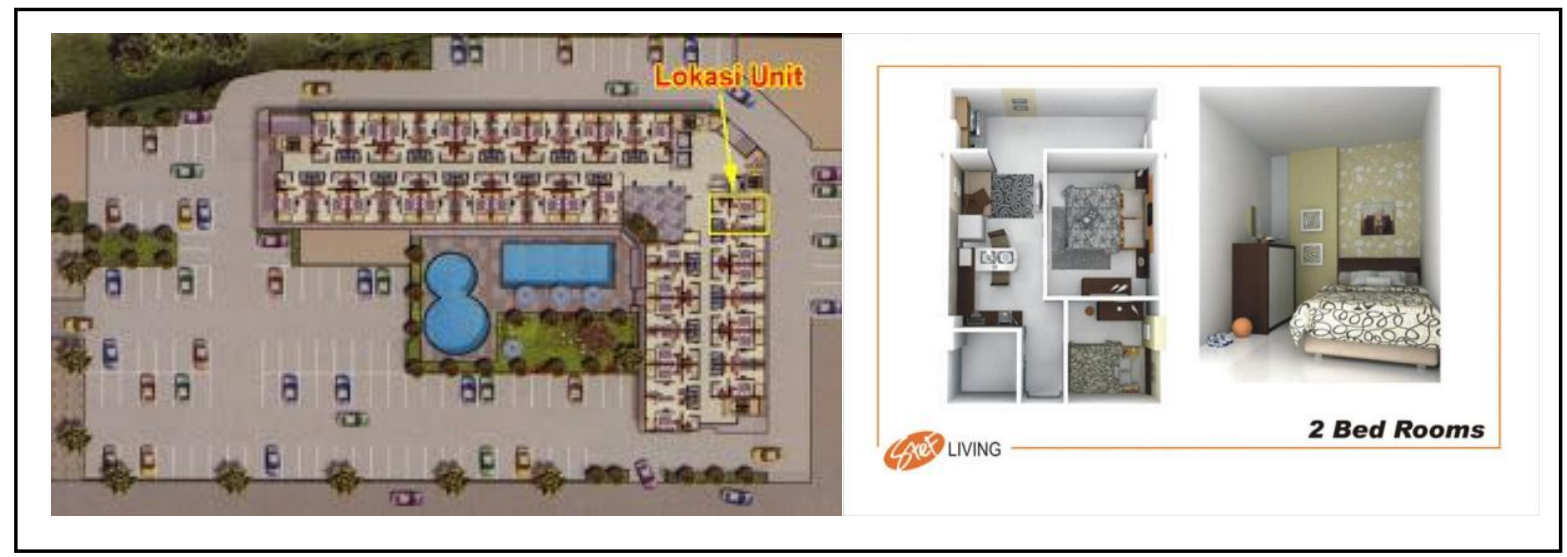

Gambar 7. Layout Apartemen XY dan Unit Kamar Apartemen.

Sumber : Dokumentasi Penulis (2016)

Apartemen XY adalah salah satu apartemen di Surabaya, memiliki tiga tipe unit apartemen yaitu tipe studio, tipe two bedroom, dan tipe three bedroom. Apartemen ini difasilitasi dengan kolam renang, gym, kantin dan taman bermain anak. Selain lokasi yang dekat dengan pusat perbelanjaan dan wisata, apartemen ini juga dekat dengan beberapa universitas, oleh karena itu banyak dari unit apartemen dihuni oleh mahasiswa. Selain mahasiswa, unit pada apartemen juga dihuni oleh pasangan keluarga baru hingga keluarga dengan beberapa orang anak. Tiap penghuni apartemen dapat memenuhi berbagai kebutuhannya dengan berbelanja di minimarket yang berlokasi dekat gedung apartemen, mereka dapat membawa barangnya. Permasalahannya apakah lebar koridor pada Apartemen $\mathrm{XY}$ sudah cukup nyaman bagi penghuninya dengan memperhatikan keseluruhan aktivitas yang rutin terjadi pada area koridor tersebut. 


\section{METODOLOGI}

Penelitian ini menggunakan metode observasi lapangan pada pukul $18.00-19.00 \mathrm{WIB}$ yang direkam dengan video. Video observasi bertujuan untuk merekam gestur yang dilakukan orang yang melalui koridor dan menganalisanya. Menganalisa data-data yang diperoleh melalui video,kemudian mengobservasi, mengolah dan mengaitkan dengan data studi literatur yang berkaitan dengan respon fisik manusia pada lingkungan koridor.

\section{STUDI PUSTAKA}

\section{A. Anthropometri dan Ergonomi pada Koridor}

Berikut ini adalah data-data anthropometri sirkulasi yang diperlukan dalam koridor secara umum. Data-data tersebut bersumber dari buku Human Dimension and Space karangan Julius Paneiro dan Martin Zelnik (1979).

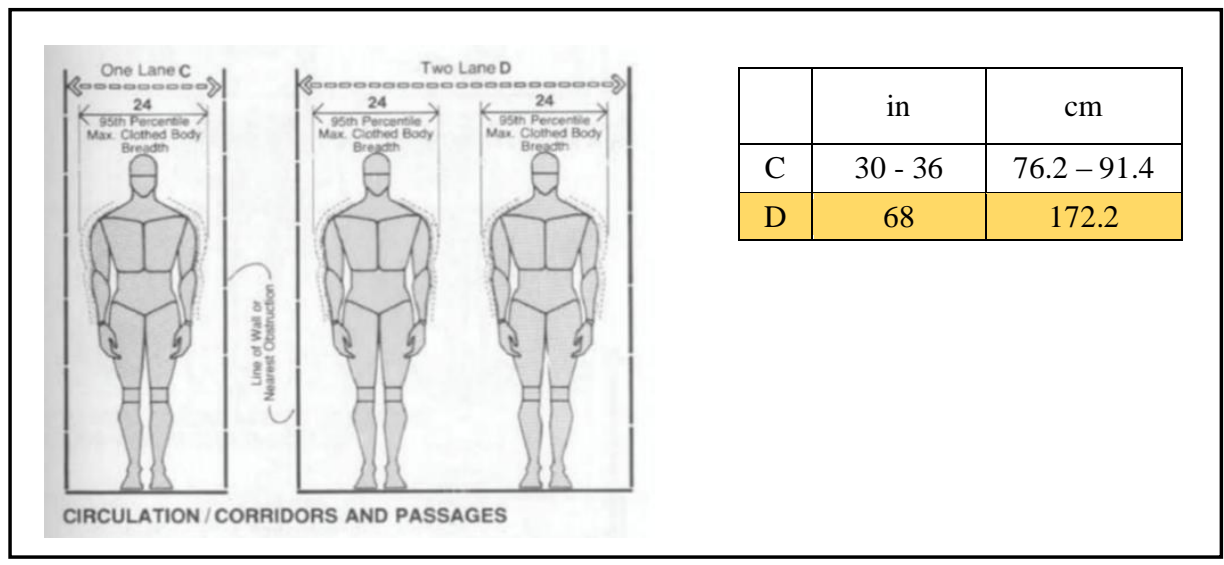

Gambar 1. Sirkulasi Pengguna Pada Koridor dalam Kondisi Berdiri Tegak untuk Aktivitas Tersebut Lebar Koridor yang Disarankan adalah $172.2 \mathrm{~cm}$.

Sumber : Buku Human Dimension and Space (Paneiro dan Zenik, 1979)

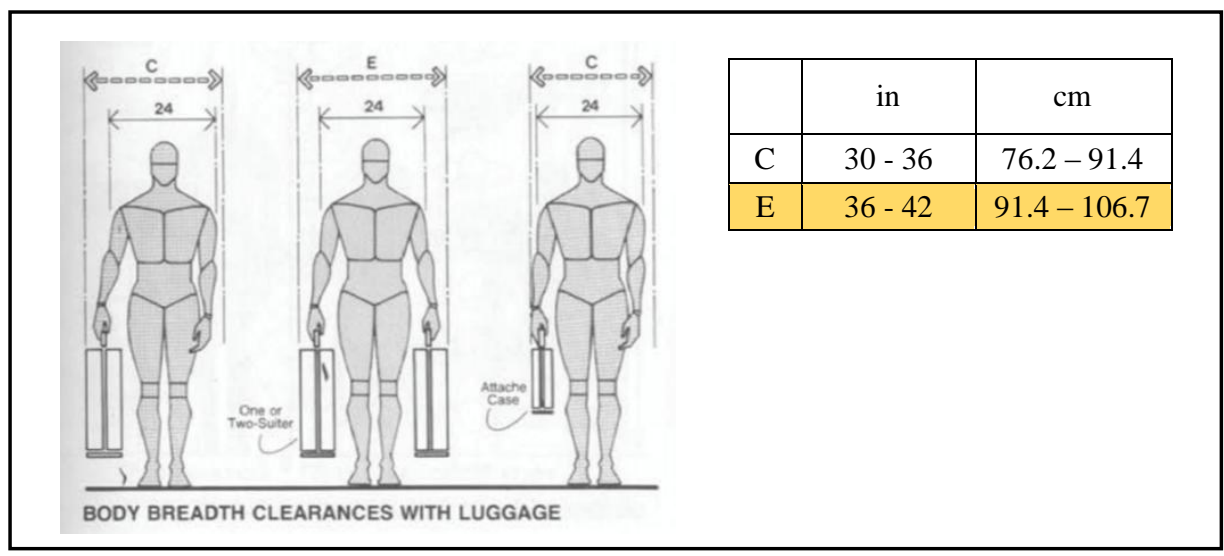

Gambar 2. Lebar Area yang Digunakan Manusia

Ketika Berdiri dengan Membawa Koper dengan Lebar Sekitar 20cm.

Sumber : Buku Human Dimension and Space (Paneiro dan Zenik, 1979) 


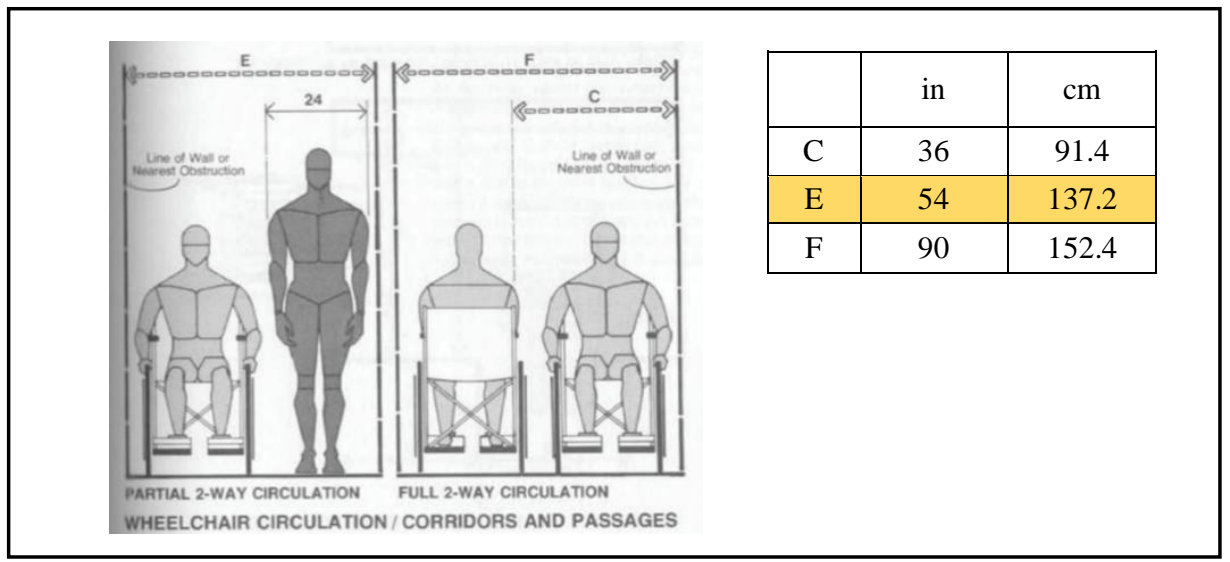

Gambar 3. Sirkulasi Ketika Berpapasan dengan Orang yang Menggunakan Kursi Roda. Sumber : Buku Human Dimension and Space (Paneiro dan Zenik, 1979)

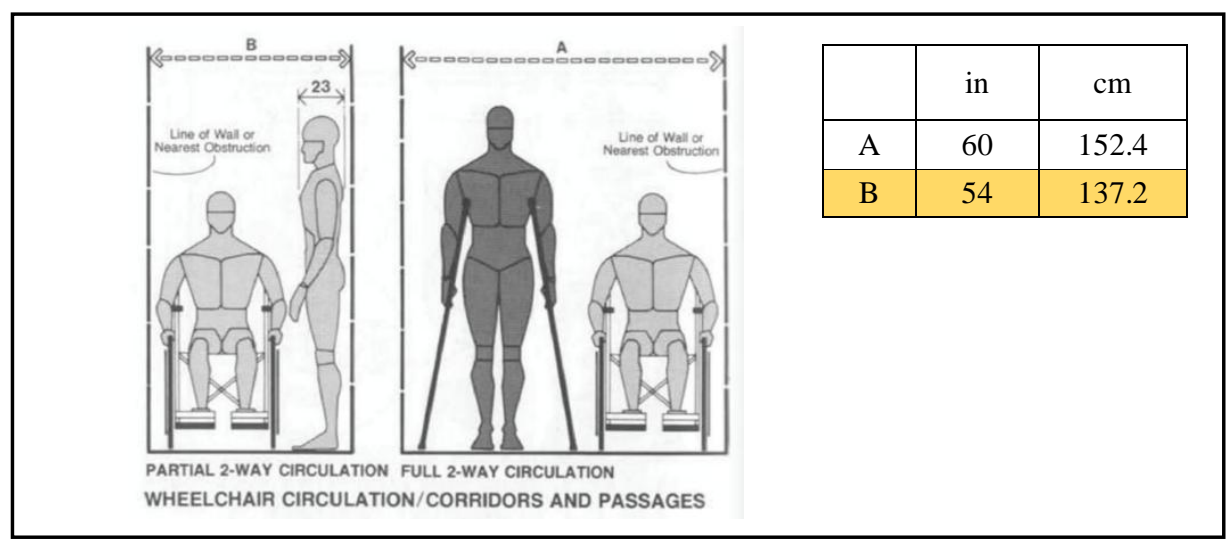

Gambar 4. Sirkulasi Penyandang Difabel pada Koridor.

Sumber : Buku Human Dimension and Space (Paneiro dan Zenik, 1979)

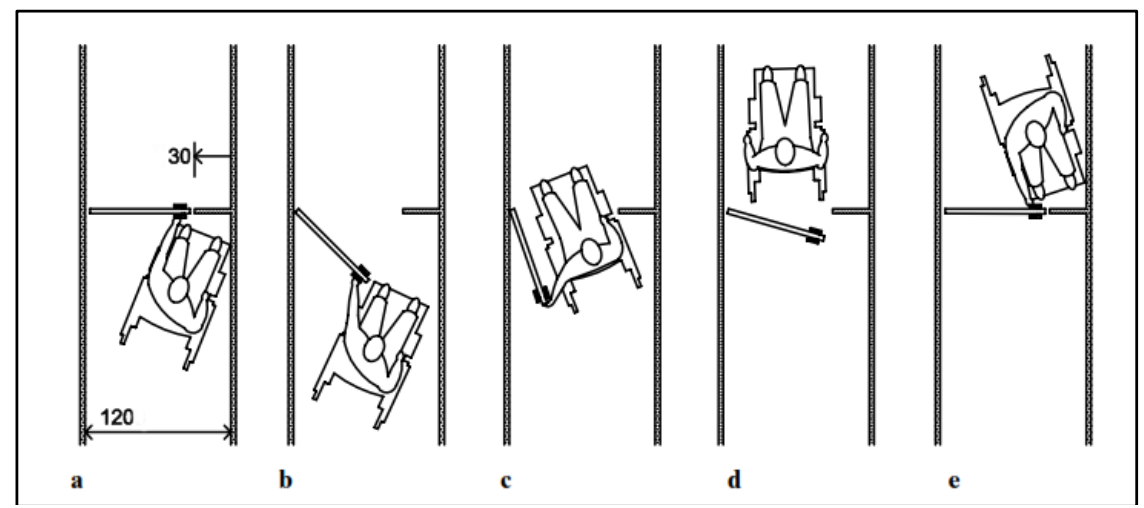

Gambar 5. Sirkulasi Pengguna Kursi Roda dengan Lebar Koridor $120 \mathrm{~cm}$ dan Menyisakan $30 \mathrm{~cm}$ Area Kosong untuk Bermanuver .

Sumber : Universal Design: A Manual of Practical Guidance for Architects (Goldsmith, Selwyn,2000) 


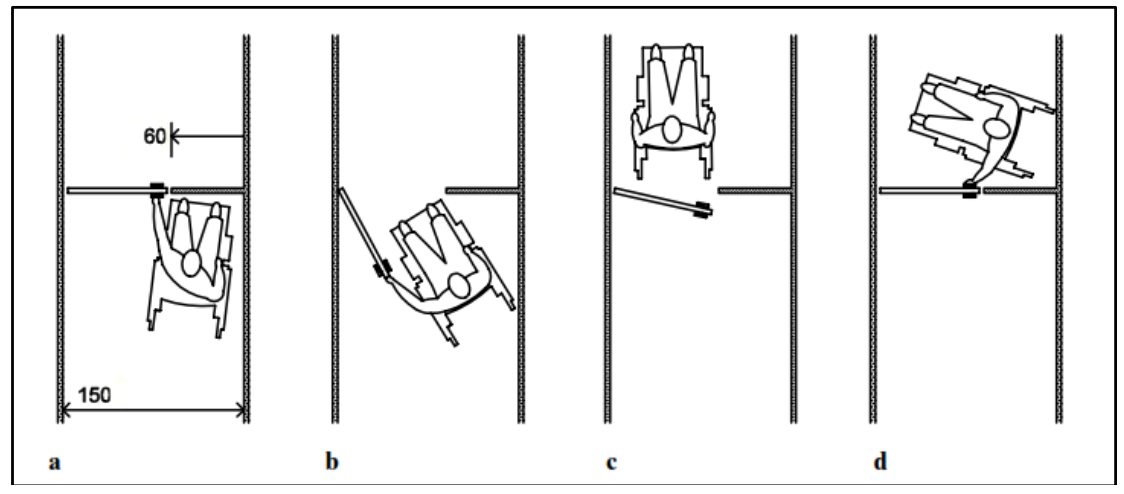

Gambar 6. Sirkulasi Pengguna Kursi Roda dengan Lebar Koridor $150 \mathrm{~cm}$ dan Menyisakan $60 \mathrm{~cm}$ Area Kosong untuk Bermanuver.

Sumber : Universal Design : A Manual of Practical Guidance for Architects (Goldsmith, Selwyn,2000)

Pada gambar 1, lebar minimum sirkulasi untuk dua individu yang berpapasan di korodor adalah $172.2 \mathrm{~cm}$. Bila pengguna membawa barang pada kedua tangannya maka memerlukan area minimal 91,4-106,7 cm (gambar 2). Kebutuhan sirkulasi bila pengguna berpapasan dengan pengguna lain yang menggunakan kursi roda, maka memerlukan lebar sirkulasi minimal 137,2 cm (dua kursi roda berpapasan) ditunjukkan pada gambar 3. Sirkulasi koridor $120 \mathrm{~cm}$ akan menyisakan $30 \mathrm{~cm}$ ruang kosong untuk bermanuver, sedangkan bila lebar koridor $150 \mathrm{~cm}$ maka akan menyisakan $60 \mathrm{~cm}$ ruang kosong untuk bermanuver. Data-data tersebut akan digunakan sebagai standar acuan dalam menentukan ergonomi pada desain koridor apartemen sehingga tercipta sirkulasi yang baik dan nyaman bagi beragam pengguna koridor.

\section{A. Pengukuran Eksisting Koridor}

Pengkuran ini meliputi pengukuran dimensi koridor serta objek-objek yang ada di dalamnya. Berbagai objek yang terdapat di dalam koridor tentu akan menentukan respon fisik pengguna koridor, maka dari itu pengukuran dimensi serta letak objek dan koridor menjadi hal yang perlu untuk dilakukan dalam penelitian ini.

\section{B. Observasi}

Observasi dilakukan dengan cara mengambil video pada pukul $18.00-19.00$ WIB dan melakukan tinjauan atas berbagai aktvitas yang dilakukan dan observasi perilaku di koridor.

\section{Observasi aktivitas}

Melalui rekaman video kami meninjau berbagai aktivitas yang dilakukan orang ketika melalui koridor. Aktivitas tersebut dapat dilakukan secara individu maupun berkelompok. Menurut Nemeth (2004) analisis aktifitas digunakan untuk mencatat segala hal yang dilakukan seseorang ketika melakukan pekerjaan. Tujuannya adalah untuk menentukan aktifitas yang terjadi pada berbagai situasi dan seberapa sering aktivitas tersebut dilakukan. Berikut ini adalah data berbagai aktivitas yang dilakukan pada koridor utama apartemen ini berdasarkan observasi, yaitu:
a) Aktivitas membawa belanjaan
b) Kurir membawa belanjaan dibantu dengan troli
c) Pergi bekerja/kuliah dengan membawa tas dan tugas 
d) Berjalan sambil menerima telepon di koridor

e) Mengecek surat di kotak surat

f) Berjalan secara berkelompok/keluarga

\section{Observasi perilaku}

Pada observasi perilaku, adalah tinjauan dari perilaku fisik yang merupakan respon pengguna atas keadaan lingkungan di koridor dengan berbagai aktivitas yang dilakukan di dalamnya.

\section{PEMBAHASAN}

Dalam penelitian ini, pembahasan akan dibatasi pada tinjauan respon fisik yang dilakukan oleh pengguna koridor Apartemen XY atas kondisi lingkungan di koridor yang dipengaruhi oleh lebar koridor serta berbagai aktivitas yang terjadi di dalamnya. Jo, dkk (2014) menyatakan bahwa lama waktu yang diperlukan untuk melalui koridor dipengaruhi oleh berbagai aspek, yaitu kepadatan populasi di koridor, lebar yang efektif, kecepatan, karakteristik alur, dan waktu yang dihabiskan untuk melalui komponen.

\section{A. Pengukuran Eksisting Koridor}

Koridor dengan panjang $30 \mathrm{~m}$, lebar $150 \mathrm{~cm}$, dan tinggi langit-langit $300 \mathrm{~cm}$ ini memiliki 1 buah kotak hydrant berdimensi panjang $70 \mathrm{~cm}$, kedalaman $20 \mathrm{~cm}$, dan tinggi 80 $\mathrm{cm}$, serta kotak surat penghuni dengan panjang $800 \mathrm{~cm}$, kedalaman $15 \mathrm{~cm}$, dan tinggi $190 \mathrm{~cm}$. Selain objek-objek yang telah disebutkan di atas, sepanjang koridor juga terdapat 5 unit kamar apartemen yang telah dihuni. Pintu masuk menuju koridor ini memiliki lebar $90 \mathrm{~cm}$ yang dapat dibuka menggunakan kartu akses penghuni. Dalam panduan universal design National Disability Authority (NDA) merekomendasikan lebar ideal koridor yang diakses publik adalah $200 \mathrm{~cm}-250 \mathrm{~cm}$ agar dapat diakses oleh pengguna secara nyaman dalam berbagai kondisi. Koridor dengan lebar kurang dari standar akan menyulitkan bagi pengguna.

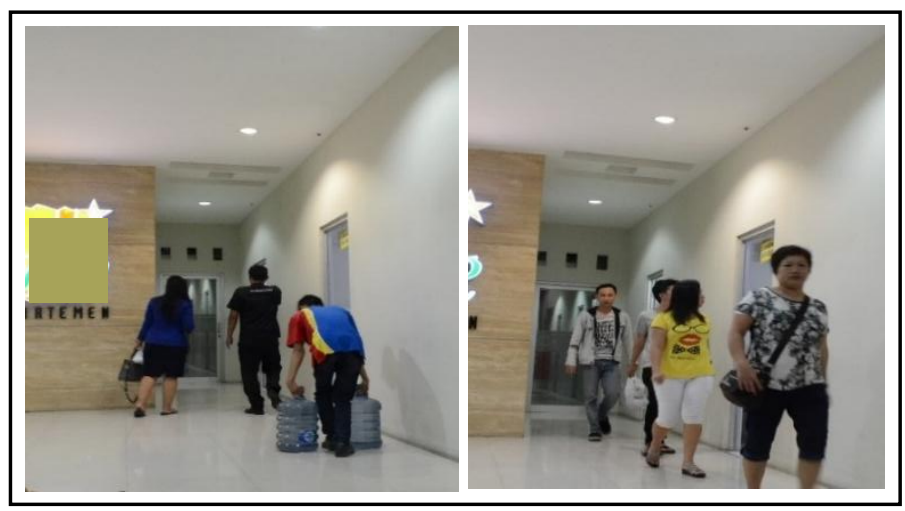

Gambar 8. Koridor Utama pada Ujung Lorong Lobby yang Menghubungkan Dengan Unit-Unit Hunian Apartemen.

Sumber : Dokumentasi Penulis (2016)

Koridor ini juga merupakan jalur yang dilalui kurir untuk membawa barang-barang pesanan penghuni apartemen 


\section{B. Studi Literatur}

Definisi dari kenyamanan menurut Slater (1985) dalam Vink (2005) adalah kondisi nyaman fisiologis, psikologis, dan fisik secara harmonis antara manusia dengan lingkungannya. Pada dasarnya kenyamanan sangat bersifat subyektif, kenyaman setiap individu memiliki standar yang berbeda namun terdapat beberapa hal yang telah disepakati secara umum tentang kenyamanan (Looze et al. 2003 dalam vink,2005):

1) Kenyamanan adalah reaksi terhadap lingkungan.

2) Kenyamanan dibangun atas subyektifitas seseorang.

3) Kenyamanan disebabkan berbagai faktor (fisiologis, psikologis, dan fisik).

Panero (1979) dalam bukunya Human Dimension and Space, merujuk pada penelitian Dr. John Fruin bahwa manusia memiliki jarak psikologis tertentu ketika berinteraksi dengan manusia. Hal tersebut dijelaskan melalui gambar dan tabel di bawah ini.

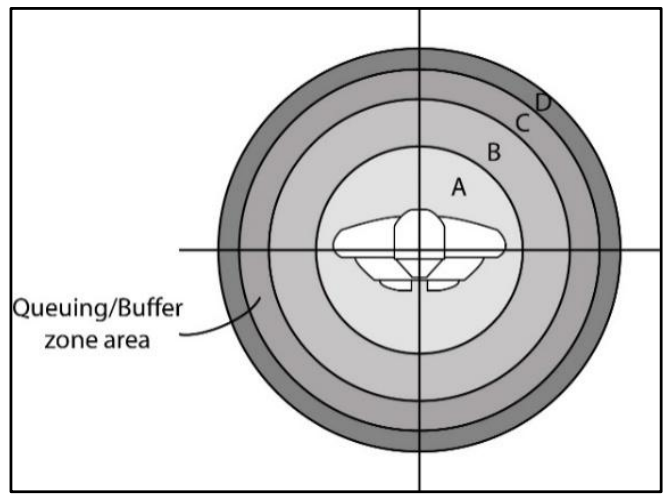

Gambar 9. Area Psikologis Manusia Ketika Berinteraksi dengan Manusia, Deskripsi Terdapat pada Tabel 1. Sumber : Buku Human Dimension and Space (Paneiro dan Zenik, 1979)

Tabel 1. Tabel ini disajikan pada buku Human Dimension and Space yang diadaptasi dari penelitian John J. Fruin, Pedestrian Planning and Design.

\begin{tabular}{|c|l|c|}
\hline Istilah & \multicolumn{1}{|c|}{ Deskripsi } & Radius \\
\hline A. Touch Zone & $\begin{array}{l}\text { Dalam area ini sering terjadi kontak fisik } \\
\text { yang tak dapat dihindari. Dalam area ini } \\
\text { gerakan terbatas sekedar bergeser, sulit } \\
\text { untuk terjadi sirkulasi yang baik. }\end{array}$ & $30.5 \mathrm{~cm}$ \\
\hline B. No-Touch Zone & $\begin{array}{l}\text { Kontak fisik dengan orang dapat dihindari } \\
\text { selama gerakan dalam area itu tidak } \\
\text { diperlukan. Memungkinkan untuk gerak } \\
\text { dalam kelompok. }\end{array}$ & $45.7 \mathrm{~cm}$ \\
\hline C. Personal Zone & $\begin{array}{l}\text { Area sirkulasi yang cukup nyaman dan jauh } \\
\text { dari bersentuhan dengan orang lain. }\end{array}$ & $53.3 \mathrm{~cm}$ \\
\hline D. Circulation & $\begin{array}{l}\text { Sirkulasi dalam area antri yang } \\
\text { memungkinkan untuk tidak mengganggu } \\
\text { orang lain. }\end{array}$ & $61 \mathrm{~cm}$ \\
\hline
\end{tabular}

(New York: Metropolitan Association of Urban Designers and Environmental Planners. 1971)

Gambar dan tabel di atas adalah rujukan data standar dalam melakukan analisa pada video hasil observasi penelitian yang telah kami lakukan. 
Susy Budi Astuti ${ }^{1}$, Aria Weny Anggraita ${ }^{2}$, M. Husnul Azar ${ }^{3}$, Angga Rubianto $^{4}$

Persepsi Terhadap Lebar Koridor Utama pada Apartemen Ditinjau dari Respon Fisik Pengguna

\section{Observasi}

\section{Analisa Video Observasi}

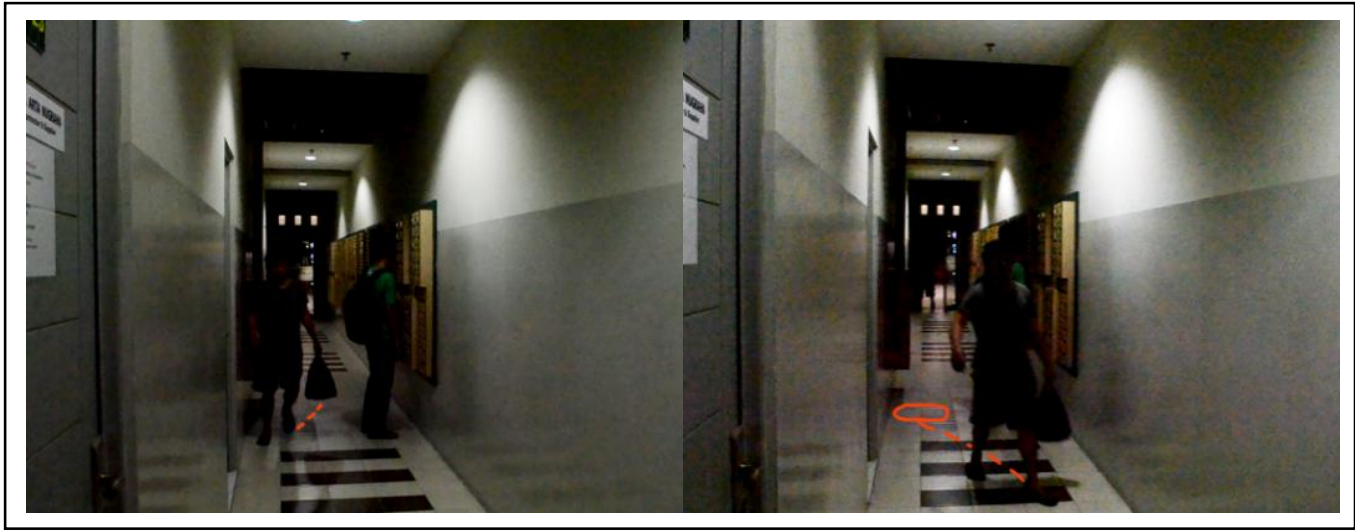

Gambar 10.Gambar Aktual Hasil Rekaman Video Observasi

Sumber : Dokumentasi Penulis (2016)

Terlihat pengguna koridor melakukan respons fisik atas kondisi di koridor yang arah geraknya ditunjukkan dengan garis merah.

Observasi kami lakukan dengan mendokumentasikan aktivitas yang dilakukan oleh pengguna koridor. Hasil dari video observasi dapat dilihat seperti pada gambar 10, kemudian dilakukan visualisasi menggunakan software CAD untuk dapat memberikan gambaran sirkulasi pada koridor.

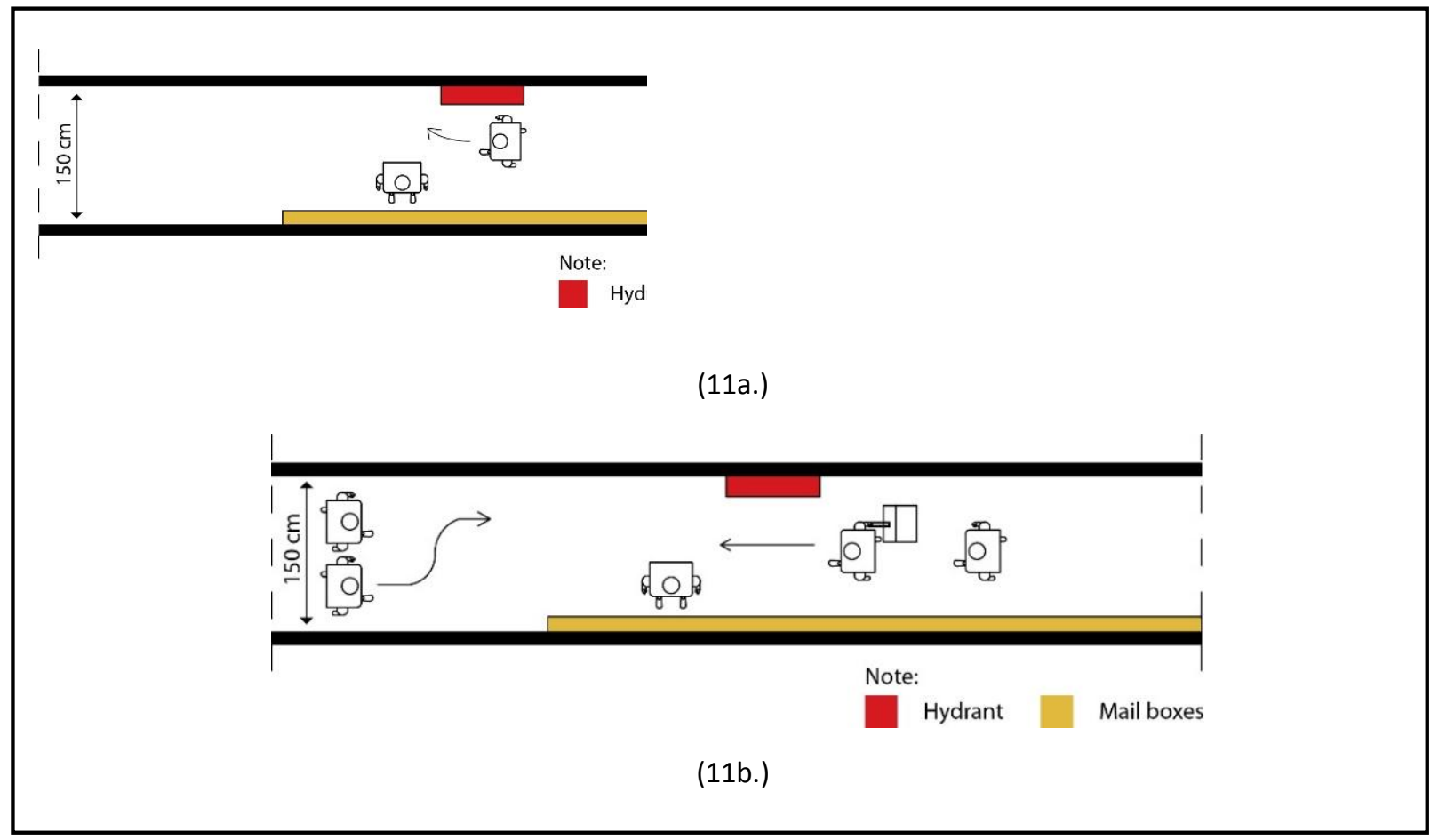

Gambar 11 (a-b). Visualisasi dari Video Observasi yang Telah Direkam Digambarkan dengan Software CAD.

Sumber : Konstruksi Penulis (2016) 
Visualisasi yang diciptakan pada software merujuk pada anthropometri manusia pada buku Human Dimension and Space. Analisa yang dilakukan melalui video dan visualisasi ini dapat memberikan gambaran akan sirkulasi pada koridor apartemen dengan berbagai aktivitas yang dilakukan.

\section{Analisa Respons Fisik}

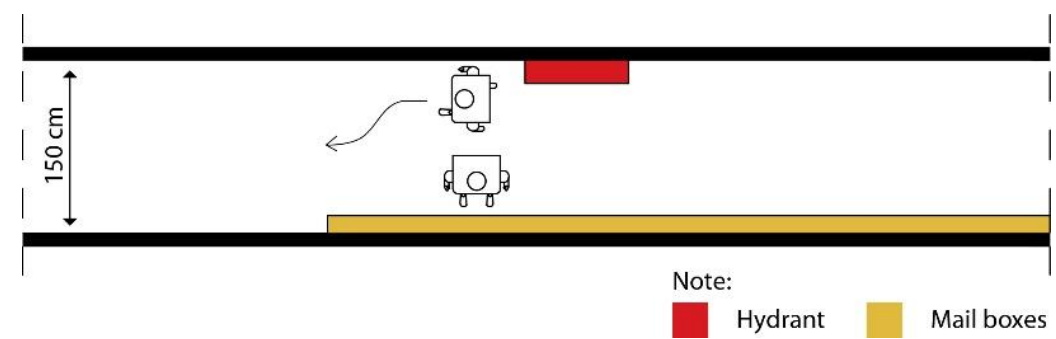

Gambar 12. Visualisasi Ketika Orang Berjalan Sendirian dan Saat Terdapat Orang Sedang Mengecek Kotak Surat.

Sumber : Konstruksi Penulis (2016)

Pada gambar di atas terlihat bahwa seseorang sedang berjalan sendirian cenderung memberikan jarak antara dirinya dengan orang yang sedang mengecek kotak surat. Meskipun dirinya tetep dapat berjalan tanpa harus bersentuhan fisik dengan orang yang sedang mengecek surat, tapi orang tersebut cenderung untuk memberi jarak. Hal ini merupakan respons fisik manusia yang dipengaruhi oleh aspek psikologis. Seperti yang telah disebutkan pada tabel 1, orang tersebut menghindar agar dirinya dengan orang yang sedang mengecek surat tetap berada pada area no-touching zone sehingga privasi mereka tidak saling terganggu.

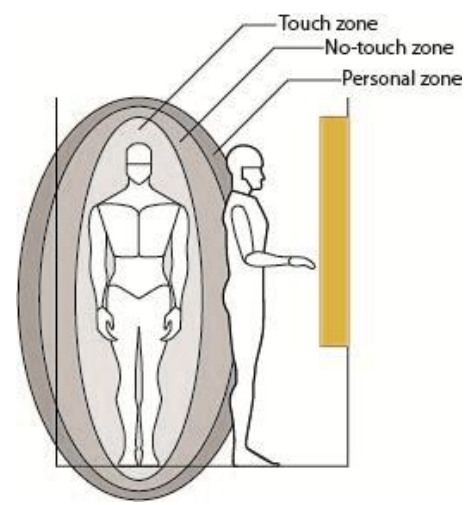

Gambar 12. Analisa Queuing Zone Aktifitas pada Gambar 11(a-b).

Berdasarkan analisa queuing zone manusia seperti ditunjukan oleh gambar 12 , terlihat bahwa aktifitas orang yang sedang mengecek surat memasuki area no-touching zone orang yang sedang berjalan melalui koridor, karena itu orang yang sedang berjalan melalui koridor tersebut cenderung untuk memberi jarak lebih jauh dengan orang yang sedang mengecek surat. Hal ini terjadi karena respons fisik manusia terhadap lingkungan di sekitarnya. Orang yang sedang berjalan secara merespons jarak yang terlalu sempit antara dirinya dengan orang yang sedang berdiri dengan sedikit bergeser ke kiri agar jarak antara dia dengan orang yang berdiri tidak masuk dalam touching zone atau tetap berada pada personal zone. 


\section{Analisa Efektifitas Koridor}

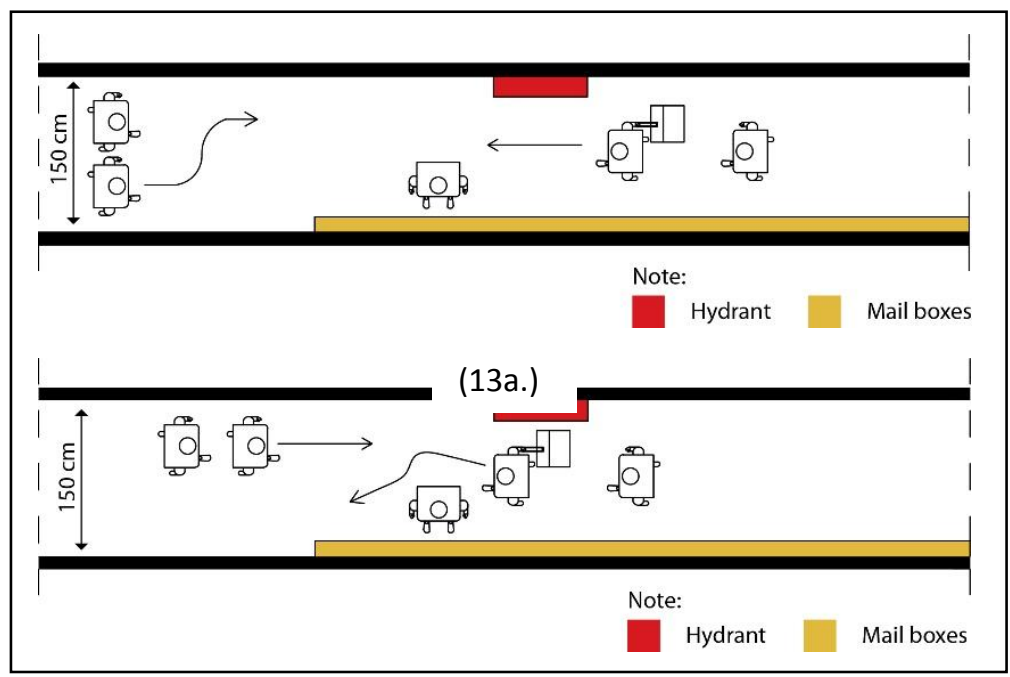

(13b.)

Gambar 13 (a-b). Visualisasi Dari Aktifitas Dua Kelompok Orang Sedang Berjalan Berlawanan di Koridor. Sumber : Konstruksi Penulis (2016)

Dalam visualisasi di atas, terlihat dua orang sedang berjalan beriringan dengan satu orang membawa koper di posisi depan menuju pintu keluar. Disisi lain terlihat dua orang yang berjalan berdampingan menuju pintu masuk. Orang dengan koper melakukan gerak berbelok menghindari orang yang sedang mengecek surat, sedangkan pada sisi lain dua orang yang berjalan berdampingan melakukan perubahan posisi beriringan agar tidak terjadi kontak dari arah berlawanan. Perubahan posisi seperti ini merupakan respon fisik manusia untuk menjaga queuing zone tiap individu agar tidak terjadi kontak fisik.

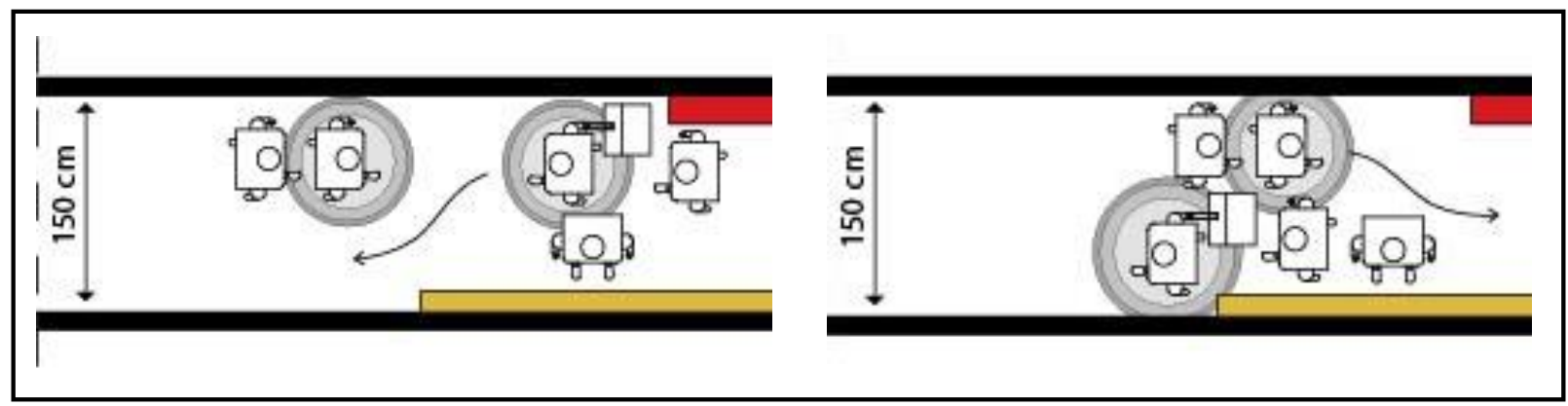

Gambar 14. Visualisasi Queuing Zone Manusia pada Aktifitas Sesuai Gambar 12. Sumber : Konstruksi Penulis (2016)

Kecenderungan manusia untuk menjaga jarak pada personal zone terlihat pada gambar di atas, dimana orang akan sedikit menjauh ketika berpapasan dengan orang lain. Kebiasaan untuk menjaga jarak ini membuat sebuah temuan bahwa sirkulasi dalam koridor tidak hanya harus memperhitungkan anthropometri, melainkan juga aspek psikologis seperti queuing zone dari tiap pengguna. Lebar koridor Apartemen XY yang hanya $150 \mathrm{~cm}$ membuat sirkulasi antar tiap pengguna menjadi kurang baik dikarenakan lebar koridor yang terlalu kecil ditambah dengan terdapat kotak surat dan hydrant yang dapat membuat koridor semakin sempit. Ditinjau dari respon fisik pada dua kegiatan di atas, terlihat bahwa koridor yang sempit dapat 
membuat dua orang yang ketika berpapasan pada jarak tertentu, orang akan memberikan respons untuk saling menjauh untuk menghindari kontak fisik satu sama lain.

Manusia memiliki jarak psikologis tertentu ketika berinteraksi dengan manusia lainnya, akan lebih nyaman bila jarak sirkulasi antara aktivitas individu yang melihat kotak surat dan individu yang melewati koridor dengan membawa tas/tas belanja tidak memasuki area notouch zone masing-masing, minimal dibutuhkan lebar koridor dengan jarak minimal dua area individu non touch zone sekitar $185 \mathrm{~cm}$ menyesuaikan aktivitas dan perlengkapan yang ada pada koridor. Menurut data antropometri dan ergonomi jarak kenyamanan sirkulasi di koridor untuk individu yang membawa tas dikedua tangan adalah min $91,4 \mathrm{~cm}$. Untuk individu dengan kursi roda lebar minimal yang dibutuhkan adalah $91,4 \mathrm{~cm}$.

Pada Apartemen XY di area koridor terdapat kotak surat dengan ukuran $800 \mathrm{~cm} \mathrm{x} 15$ $\mathrm{cm}$ x $190 \mathrm{~cm}$ (PxLxT), dan hidran dengan ukuran $70 \mathrm{~cm}$ x $20 \mathrm{~cm}$ x $80 \mathrm{~cm}$ (PxLxT), maka lebar koridor yang cukup nyaman untuk apartemen XY adalah: (mengabaikan ukuran Hidran)

$=($ Jumlah individu yg berpapasan $\mathrm{x}$ uk. Kenyamanan individu/no-touch zone $)+$ uk.lebar kotak surat

$=(2 \times 91,4) \mathrm{cm}+15 \mathrm{~cm}$

$=197,8 \mathrm{~cm}$

Dengan mempertimbangkan individu yang menggunakan kursi roda dan sirkulasi notouch zone, maka diperoleh lebar koridor yang nyaman untuk Apartemen XY adalah 197,8 $\mathrm{cm}$.

\section{KESIMPULAN}

Dalam mendesain lebar sebuah koridor diperlukan pemahaman mendalam tentang beragam aktivitas yang terjadi pada koridor tersebut dan juga harus mempertimbangkan aspek psikologis manusia. Persoalan kenyamanan adalah persepsi yang tercipta pada tiap-tiap individu dan dapat dipengaruhi oleh lingkungan sekitar, kondisi nyaman, kurang nyaman, atau tidak nyaman akan membuat manusia melakukan respon baik secara psikologis, fisiologis, maupun fisik. Setiap orang memiliki queuing zone masing-masing sehingga cenderung untuk memberikan jarak agar orang disekitarnya tetap berada di personal zone.

Studi ini berfokus pada lebar sebuah koridor dan respon psikologis terhadap queuing zone serta respon fisik pengguna. Hubungan antara queuing zone serta respon fisik yang ditimbulkan dalam studi ini dapat menjadi sebuah acuan dalam mendesain lebar sebuah koridor karena ini adalah respon fisik yang paling sering dijumpai ketika orang yang tidak saling kenal berpapasan. Lebar koridor Apartemen XY yang hanya $150 \mathrm{~cm}$ membuat sirkulasi antar tiap pengguna menjadi kurang nyaman dikarenakan lebar koridor yang terlalu kecil ditambah dengan terdapat kotak surat dan hydrant yang dapat membuat koridor semakin sempit.Mempertimbangkan aktivitas kebutuhan dan respon fisik pengguna pada saat melewati koridor Apartemen XY maka lebar yang nyaman agar pengguna bisa leluasa adalah 197,8 cm.

\section{DAFTAR PUSTAKA}

Goldsmith, Selwyn. 2000. Universal Design: A Manual of Practical Guidance for Architects. Oxford, Architectural Press.

Jo, A., Sano, T., Ikehata, Y., Ohmiya, Y., 2014. "Analysis of crowd flow capacity through a door connected to a crowded corridor", in: The Conference on Pedestrian and Evacuation Dynamics 2014 (PED2014), pp. 10-18.

Nemeth, Christopher P. 2004. Human Factors Method for Design.New York, CRC Press 
Susy Budi Astuti ${ }^{1}$, Aria Weny Anggraita ${ }^{2}$, M. Husnul Azar ${ }^{3}$, Angga Rubianto ${ }^{4}$

Persepsi Terhadap Lebar Koridor Utama pada Apartemen Ditinjau dari Respon Fisik Pengguna

Paneiro, Julius \& Zelnik, Martin. 1979. Human Dimension and Space. New York, Whitney Library of Design

Vink, Peter. 2005. Comfort and Design: Principles and Good Practice. New York, CRC Press. 